\title{
OUTCOME OF TEENAGE PREGNANCY
}

Tripathi $\mathrm{M}^{1}$, Sherchan $\mathrm{A}^{2}$

\section{ABSTRACT}

INTRODUCTION: Teenage pregnancy is coming up as one of the most important social and public health problem all over the world. Teenage pregnancy is a common social phenomenon with public health and medical consequences worldwide. The study was done to compare obstetric and perinatal outcome in teenage and non-teenage pregnancies.

METHODS: This is a comparative study. The study duration was from 10th January 2010 to 9th January 2012. All teenage mothers (aged 13-19 completed years at delivery) delivering in the Gandaki Medical College(GMC) hospital, Pokhara were taken as cases (study group). Next 2 consecutive deliveries in the age group of 20-30 year were selected as control for each case

RESULTS: The incidence of complications in teenage primigravida (study group) compared with non-teenage (control group) deliveries were anemia (20\% vs $6 \%$ ), preterm labour $(20 \%$ vs $7 \%)$, Urinary tract infection(UTI) $(8 \%$ vs $4 \%)$, preeclampsia ( $4 \%$ vs $2 \%$ ) and Prelabour Rupture of Membrane(PROM) (10\% vs 4\%). Similarly, abnormal presentation (6\% vs $2 \%$ ), placenta praevia (4\% vs 1\%), Fetal distress(FD) ( $8 \%$ vs 3\%), Cephalo Pelvic Disproportion(CPD) (6\% vs $2 \%)$ and Low Birth Weight(LBW) (24\% vs $9 \%$ )were recorded respectively.

In study group, $58 \%$ of the patients were delivered vaginally \& $24 \%$ were delivered by caesarean section, $6 \%$ delivered by breech and $12 \%$ of patients had instrumental delivery. In non-teenage group, $74 \%$ of the patients delivered vaginally $\&$ $14 \%$ were delivered by caesarean section, $4 \%$ delivered by breech and $8 \%$ of patient had instrumental delivery.

CONCLUSION: Teenage pregnant mothers had high rate of inadequate prenatal care, suffered more from anemia, UTI, \& were more likely to deliver preterm and had low birth weight babies. They had high rates of operative and instrumental delivery.

KEY WORDS: Low Birth Weight, Obstetrical outcome, Prematurity, Teenage pregnancy

1. Senior Consultant, Department of Obstetrics \& Gynaecology, Gandaki Medical College \& Teaching Hospital, Pokhara, Nepal

2. Consultant, Department of Obstetrics \& Gynaecology, Gandaki Medical College \& Teaching Hospital, Pokhara, Nepal

\section{For Correspondence}

Dr.Malati Tripathi M.D., D.G.O., R.C.O.G.

Senior Consultant,

Department of Obstetrics \& Gynaecology

Gandaki Medical College, Pokhara, Nepal.

Email: drmalatitripathi@hotmail.com 


\section{INTRODUCTION}

Teenage pregnancy is a common social phenomenon with public health and medical consequences worldwide. In this context, adolescent pregnancy has been a problem with adverse obstetric and neonatal outcomes being influenced by biological immaturity, unintended pregnancy, inadequate perinatal care, poor maternal nutrition, and stress. Socioeconomic, cultural, geographic and racial factors are also associated with teenage pregnancy and poor pregnancy outcome. ${ }^{1}$

WHO report 2005, shows that one woman dies of pregnancy and childbirth related complications every minute, i.e. more than half a million every year. ${ }^{2}$ When a girl becomes a mother before she is physically and emotionally ready, the results are even more tragic. One in every ten births worldwide, is to a mother who is still herself a child. ${ }^{3}$ Worldwide more than 13 million adolescent girls give birth each year, with more than 9 out of 10 births taking place in the developing world. ${ }^{4}$ Complications from pregnancy and childbirth are the leading causes of death of young women aged 15-19 years in the developing world. ${ }^{5}$ Owing to the rapid growth and development of the body, teenage is normally a period of high nutritional needs. Pregnancy imposes additional nutritional demands on the growing body and may rapidly deplete already limited reserve. ${ }^{6}$

Teenage pregnancy is coming up as one of the most important social and public health problem all over the world with a varying prevalence rate. In recent years, the incidence is increasing due to early onset of puberty, early sexual activity in girls and relative lack of education on contraceptive methods. It is well known, that teenagers face greater risks of pregnancy than the women in their adulthood.

Teenage pregnancies represent a high-risk group in reproductive terms because of the double burden of reproduction and growth. Complications of pregnancy and childbirth are the leading cause of mortality among girls aged $15-19$ years in developing countries. ${ }^{8}$

The combination of poor nutrition and early child bearing expose young women to serious health risks during pregnancy and childbirth, including damage to the reproductive tract, pregnancy related complications, such as anaemia, pregnancy induced hypertension, preterm labour, cephalo-pelvic disproportion, maternal mortality, perinatal and neonatal mortality, and low birth weight. ${ }^{9}$ A WHO study, stated that adolescents aged $<16$ years face four times the risk of maternal death than women aged in their $20 \mathrm{~s}$, and the death rate of their neonates is about $50 \%$ higher. ${ }^{10}$ This study aims to explore obstetric and perinatal outcome in teenage and non-teenage pregnancies in patients attending our hospital.

\section{MATERIAL AND METHODS}

The study undertaken, was observational type, with two groups-cases and comparison. Primigravida teenage mothers aged 13-19 years were regarded as the cases (group A) while primigravida adult mothers aged 20-30 years formed the comparison group (group B). Primigravida women were selected to eliminate the influence of parity. Ages above 30 years were excluded from the study. Total number of cases was 150 , with 50 pregnancies in study group and 100 pregnancies in control group.

Women with mostly the medical and obstetric complications were included in this study. For each case, next two consecutive singleton deliveries in the age-group of 20-30 years were selected for comparison.

The study was conducted at Gandaki Medical College Teaching hospital, Pokhara, Nepal, over a period of 2 years, from 10th January 2010 to 9th January 2012.

Data were collected through interviews and by observations using the pretested and predesigned performa. The first contact with the study participants for data collection began immediately after admission in maternity ward or pre labour room or labour room. Mode of delivery and perinatal outcomes were observed and Apgar score was calculated at the first minute and the fifth minute after birth. The study participants were interviewed using the questionnaire. Data were verified, and missing information was collected from the antenatal records. The data were entered in SPSS 17 and analyzed using chi square test.

\section{RESULTS}

Table 1: Maternal age and mode of delivery

\begin{tabular}{|c|c|c|c|c|c|c|}
\hline \multirow[t]{2}{*}{ Mode of Delivery } & SVD & $\begin{array}{l}\text { Breech } \\
\text { Delivery }\end{array}$ & $\begin{array}{l}\text { Instrumental } \\
\text { Delivery }\end{array}$ & LSCS & Total & Pvalue \\
\hline & № $(\%)$ & № $(\%)$ & $\mathrm{N}_{0}(\%)$ & $\mathrm{No}(\%)$ & & \multirow{3}{*}{0.26} \\
\hline Study Group "A" & $29(58)$ & $3(6)$ & $6(12)$ & $12(24)$ & 50 & \\
\hline Control Group "B" & 74 (74) & $4(4)$ & $8(8)$ & $14(14)$ & 100 & \\
\hline
\end{tabular}

In study group, fewer percentages were delivered vaginally as compared to non-teenage group but the difference in mode of delivery in two groups was not significant. 
Table 2: Maternal age and genital tract injury

\begin{tabular}{|c|c|c|c|c|c|c|c|}
\hline $\begin{array}{l}\text { Maternal age } \\
\text { and genital tract } \\
\text { injury }\end{array}$ & $\begin{array}{l}\text { Perineal } \\
\text { Tear }\end{array}$ & Episiotomy & $\begin{array}{l}\text { Cervical } \\
\text { Tear }\end{array}$ & $\begin{array}{l}\text { Perineal } \\
\text { Hematoma }\end{array}$ & $\begin{array}{l}\text { Without } \\
\text { genital } \\
\text { tract } \\
\text { injury }\end{array}$ & Total & $\begin{array}{l}P \\
\text { value }\end{array}$ \\
\hline & No (\%) & No (\%) & No (\%) & No (\%) & No (\%) & & \\
\hline Study Group "A" & $8(16)$ & $38(76)$ & $1(2)$ & 1 (2) & $2(4)$ & 50 & \multirow[t]{2}{*}{0.28} \\
\hline $\begin{array}{l}\text { Control Group } \\
\text { "B" }\end{array}$ & $12(12)$ & $70(70)$ & $1(1)$ & $1(1)$ & $16(16)$ & 100 & \\
\hline
\end{tabular}

The teenage group mothers suffered more genital tract injuries than the control group women but the difference was not significant.

\section{Table 3: Maternal age and obstetric complications}

\begin{tabular}{|l|l|l|l|}
\hline \multirow{2}{*}{$\begin{array}{l}\text { Obstetric } \\
\text { complication }\end{array}$} & Study Group “A" & Control Group "B" & \multirow{2}{*}{ P value } \\
\cline { 2 - 3 } & No (\%) & No (\%) & \\
\hline Anemia & $10(20)$ & $6(6)$ & 0.009 \\
\hline Preterm labour & $10(20)$ & $7(7)$ & 0.018 \\
\hline UTI & $4(8)$ & $4(4)$ & 0.304 \\
\hline Pre eclampsia & $2(4)$ & $2(2)$ & 0.474 \\
\hline PROM & $5(10)$ & $4(4)$ & 0.145 \\
\hline $\begin{array}{l}\text { Abnormal } \\
\text { presentation }\end{array}$ & $3(6)$ & $2(2)$ & 0.198 \\
\hline Placenta praevia & $2(4)$ & $1(1)$ & 0.216 \\
\hline Fetal distress & $4(8)$ & $3(3)$ & 0.171 \\
\hline C P D & $3(6)$ & $2(2)$ & 0.198 \\
\hline Low birth weight & $12(24)$ & $9(9)$ & 0.013 \\
\hline
\end{tabular}

The incidence of complications of delivery in teenage primigravidae group compared with non-teenage group was higher. Anemia, preterm labour and low birth weight of baby were significantly higher in teenage group.

\section{DISCUSSION}

The teenage is defined as young women between the ages of 13 years and 19 years. Age between 20 and 30 years was considered for comparison. This study found that teenage mothers had a higher incidence of anemia. The incidence rate of anaemia among teenage pregnancies was $20 \%$. The increased risk of this complication was most likely to have resulted from poor nutritional habits and low calorie intake by teenage mothers similar to that found by Suebnukarnet al. ${ }^{11}$

In current study teenage mothers had higher incidence of anemia than their controls. Teenage mothers are more likely to be in worse nutritional conditions before conception than older women, and the effects of poor nutrition are exacerbated by increased use of essential substrates in adolescent. ${ }^{12}$

Preterm labour is another common complication in teenage pregnancies. The incidence of preterm labour among teenage pregnancies was $20 \%$, similar to that observed by Eureet al. ${ }^{13}$ The increased risk of preterm labour may be due to poor nutrition, inadequate antenatal care and lower levels of education. An increased risk of preterm delivery was associated with young maternal age in both developed and developing countries. In current study, the frequency of prematurity was also high; this finding is supported by many authors who have suggested that adolescent pregnancies are associated with increased risk of preterm labor. ${ }^{14}$

Prematurity plays the greatest role in this condition, but fetal growth restriction which can result from significantly reduced nutrition in adolescent mother is also a risk factor. Up to certain extent, these problems are associated with poor prenatal care \& poverty of adolescent mothers. ${ }^{12}$ The significant difference in neonatal outcomes between teenage and adult mothers was in birth weight. A higher proportion of teenage mothers gave birth to LBW babies. This is usually due to biological immaturity and poor socio-demographic environment. The significant difference in neonatal outcomes between teenage and adult mothers was birth weight. A higher proportion of teenage mothers gave the low birth weight infants. This may be due to biological, immaturity and poor socioeconomic environment. This finding is also consistent with many studies. ${ }^{15}$

Regarding the mode of delivery, the operative vaginal delivery and cesarean delivery in adolescent pregnant women are higher compared with pregnant adult women in this study. We observed that the most common cesarean indication of patients was cephalo-pelvic disproportion and acute fetal distress in adolescent pregnancy. In the literature, related to the surgical indications for cesarean delivery, cephalo-pelvic disproportion, presentation abnormalities, breech delivery and pregnancy-induced hypertension were declared as causes in adolescent pregnancies. ${ }^{16}$ Some of the explanations proposed for these adverse birth outcomes are biological. Biological immaturity in teenage mothers itself is an inherent risk factor for poor outcome and even adequate prenatal care does not completely eliminate the risk. Two general features of biologic immaturity could have a role in increasing the risk of adverse outcomes: a young gynecologic age (defined as conception within two years after menarche). ${ }^{17}$ And the effect of a girl, becoming pregnant before her own growth has ceased, thus competing with the developing fetus for nutrients adding to its detriment. Immaturity of the uterine or cervical blood supply may predispose teenage mothers to sub clinical infection, an increase in prostaglandin production and a consequent increase in the incidence of preterm delivery. ${ }^{18}$

The present data, suggest that maternal and fetal complications occur more frequently in the young primigravida. There was a higher incidence of hypertension, 
premature onset of labour and low birth weight, acute fetal distress, instrumental delivery and postpartum haemorrhage in this age group. Many studies have reflected poor perinatal outcome in the form of LBW, preterm delivery and increased perinatal mortality. ${ }^{19}$ This is in accordance with the present one. Teenage mothers are associated with high rate of maternal and fetal complications particularly in developing countries with limited obstetric facilities. ${ }^{20}$

\section{CONCLUSION}

This study shows that teenage mothers suffer with anemia, urinary tract infections and obstetric complications. They were more likely to deliver preterm and had LBW babies. They had higher rates of obstetric intervention. We should aim to reduce the incidence of teenage pregnancies to minimize the adverse outcomes on young mothers. Greater emphasis should be placed on sex education and contraception to avoid teenage pregnancy and enable teenagers to achieve their full potential in life and improve maternal and child health.

\section{REFERENCES}

1. Oboro VO, Tabowei TO, Jemikalajah JJ, Bosah JO, Agu D. Pregnancy outcomes among nulliparous teenagers in suburban Nigeria. J Obstet Gynaecol 2003;23:166-9. http://dx.doi.org/ $10.1080 / 0144361031000074718$

2. The World Health Report (2005). Make every mother and child count.(WHO)

3. American College of Obstetricians and Gynaecologists (1993). Adolescent pregnancy fact sheet. Washington DC.

4. World Health Organization (2003). Child and adolescent health and development progress report 2002, Geneva, 79.

5. UNICEF (2001). Too old for toys, too young for motherhoodEarly marriage: Child spouses. Innocenti Digest, No. 7, UNICEF Innocenti Research Centre, Florence.

6. Miguel OD. Teenage sexual behaviour and pregnancy: trends and determinants. Prog Obstet Gynaecol 2003;15:123-133.

7. Lee MC, Suhng LA, Lu TH, Chou MC. Association of parental characteristics with adverse outcomes of adolescent pregnancy. Fam Pract 1998; 15:336-342.http://dx.doi.org/10.1093/fampra /15.4.336

8. Mayor S. Pregnancy and childbirth are leading causes of death in teenage girls in developing countries. BMJ 2004;328:1152. http://dx.doi.org/10.1136/bmj.328.7449.1152-a

9. World Health Organization. Towards adulthood: exploring the sexual and reproductive health of adolescents in South Asia. Geneva: World Health Organization, 2003. 244 p.

10. Braine T (2009) Adolescent pregnancy: a culturally complex issue. Bull World Health Organ 87(6):41011. http://dx.doi.org /10.2471/BLT.09.020609

11. Suebnukarn K, Phupong V.Pregnancy outcomes in adolescent $<$ 15 years old.J Med Assoc Thai 2005;88:1758-62.

12. Jolly MC, Sebire N, Harris J, Robinson S, Reganl. Obstetric risk of pregnancy in women less than 18 years old. Obstet Gynaecol 2000 ; 96(6): 962 - 6. http://dx.doi.org/10.1016/S0029-7844 (00) $01075-9$

13. Eure CR, Lindsay MK, Graves WL. Risk of adverse pregnancy outcomes in young adolescent parturients in an inner-city hospital. Am JObstet Gynecol 2002;189:918 20.http:// dx.doi.org/10.1067/mob.2002.123986

14. Gordon CS, Jill PP. Teen age pregnancy and risk of adverse perinatal outcomes. Associated with first and second births. Population based retrospective cohort study B MJ. 2001;323:15.

15. Isaranurug S,Mosuwan L,Choprapawan C. Differences in socioeconomic status, service utilization, and pregnancy outcomes between teenage and adult mothers. JMed Assoc Thai 2006;89:145-51.

16. Yildirim Y, Inal MM, Tinar S. Reproductive and Obstetric Characteristics of Adolescent Pregnancies in Turkish Women. J Pediatr Adolesc Gynecol 2005;18:249-53. http://dx.doi.org /10.1016/j.jpag.2005.05.003

17. Scholl TO, Hediger ML, Salmon RN, Belsky DH, Ances IG. Association between low gynaecological age and preterm birth. Paediatr Perinat Epidemiol 1989;3 :357-66.http://dx.doi.org /10.1111/j.1365-3016.1989.tb00524.x

18. Scholl TO, Hediger ML, Ances IG, Cronk CE. Growth during early teenage pregnancies. Lancet 1988;1:70102.http://dx.doi.org/10.1016/S0140-6736(88)91494-8

19. Fraser AM, Fraser JE, Ward RH. Association of Young Maternal Age with Adverse Reproductive Outcomes. NEJM 1995; 332:1113-18.http://dx.doi.org /10.1056 /NEJM1 995042733 21701

20. Moini A, Riazi K, Mehr parvar A.H. Pregnancy and labour complication in teenagers in Tehran. Inter J Obstet Gynaecol 2002;78:245-7. http://dx.doi.org/10.1016/S0020-7292(02) 00141-8. 